Peter G. Erdmann

Laurien L. Teunissen

Frank R. van Genderen

Nicolette C. Notermans

Eline Lindeman

Paul J.M. Helders

Nico L.U. van Meeteren

\title{
Functioning of patients with chronic idiopathic axonal polyneuropathy (CIAP)
}

Abstract Although patients with Chronic Idiopathic Axonal Polyneuropathy (CIAP) report a slow deterioration of sensory and motor functions, the impact of this deterioration on daily functioning has not yet been investigated in detail. The first aim of this crosssectional study involving 56 patients with CIAP was, therefore, to assess patients' functioning with use of the International Classification of Functioning, Disability and Health (ICF). The second aim was to find determinants of walk-

N.L.U. van Meeteren, PT, PhD

Program 'Master of Science in Physiotherapy-Research'

Utrecht University

P.O. Box 85500

3508 GA Utrecht, The Netherlands

P.G. Erdmann, PT, MSc ( $\square)$

Dept. of Neurology and Neurosurgery F.00.810

University Medical Center Utrecht P.O. Box 85500

3508 GA Utrecht, The Netherlands

Tel.: +31-30-2508831

Fax: +31-3002505450

E-Mail: perdmann@umcutrecht.nl ing ability, dexterity, and autonomy. Fatigue and limited walking ability were present in most patients and differed considerably. In regression models, age, muscle strength, and fatigue together explained $63 \%$ of the variance in walking ability, which by itself explained almost $50 \%$ of the variance in patients' autonomy indoors and outdoors ( $42 \%$ and $49 \%$, respectively). Muscle strength and sensory function scores together explained $30 \%$ of the variance in dexterity scores, which in turn explained only $13 \%$ of the variance in autonomy indoors. The diminished autonomy of patients with CIAP might be improved by reducing fatigue, by means of training, and by improving walking ability.

Key words chronic idiopathic axonal polyneuropathy . CIAP $\cdot$ functioning

\section{Introduction}

Even after extensive clinical evaluation and long term follow up, a cause of chronic axonal polyneuropathy cannot be found in $10-18 \%$ of patients [1], and in these cases the disorder is termed Chronic Idiopathic
Axonal Polyneuropathy (CIAP) [2,3]. The mean age of onset of CIAP is 57 years, with a male predominance. The patients have slowly progressive sensory and motor impairments, and some patients experience neuropathic pain [4]. The impact of these progressive impairments and pain on functioning has not 
been investigated in detail. Functioning is mostly assessed using instruments with broad grading definitions (e.g. Rankin Scale). As the cause of CIAP is unknown, treatment of the disease itself is not possible. Exercise therapy is often advised, but the benefits on functioning have not been studied.

According to the International Classification of Functioning, Disability and Health (ICF) of the World Health Organization, functioning encompasses (the interactions of) all body functions and structures (e.g. muscle strength), activities (e.g. walking ability), and social participation, taking into account personal (e.g. gender, age) as well as environmental factors (e.g. workplace, assistant devices) [5] (Fig. 1). Studies of functioning may provide information about which interventions may be beneficial [6-8]. For patients with CIAP it is our assumption that fatigue, walking ability, and dexterity may play a determinant role in patients' autonomy.

The first aim of this study was to assess the functioning of patients with CIAP, with use of the ICF. The second aim was to investigate which body functions (muscle strength, sensory function, pain, fatigue, and balance) best explain variance in activity scores (walking ability and dexterity) and participation (autonomy), as well as which activities best explain variance in participation scores.

\section{Materials and methods}

\section{Patients}

Fifty-six clinically stable patients diagnosed with CIAP [2], identified from a database of the outpatient clinic of the Department of Neuromuscular Diseases of the University Medical Center Utrecht, the Netherlands, were invited to participate in the study when they came for their annual check-up. All patients agreed to have their data anonymously entered into the database. The ethics committee of the UMC Utrecht confirmed that no formal approval for the use of anonymous clinical databases is needed.

\section{Design}

The functioning of the 56 patients was evaluated in a cross-sectional study from September to December 2003. All measurements were taken by two examiners (LLT [neurological examination] and PGE [performance-based tests]). Both investigators had more than 5 years of clinical experience with this patient group and with the instruments used. First, demographic data were registered and patients were classified into subgroups using the Modified Rankin Scale (MRS) [9]. Secondly, functioning of the arms and legs (maximal isometric muscle strength, sensory function, presence of pain [yes/no], dexterity, walking ability, and the use of walking aids [i.e. rollator, crutches, cane, ankle-foot orthosis] [yes/no]) were investigated, as well as patients' self-reported fatigue, balance disorders, and self-reported autonomy indoors and outdoors. The choice of the instruments used was based on the clinical spectrum of CIAP $[2,7,10]$ and guided by the current views and opinions of the ICF. All assessments were done in a quiet and comfortable

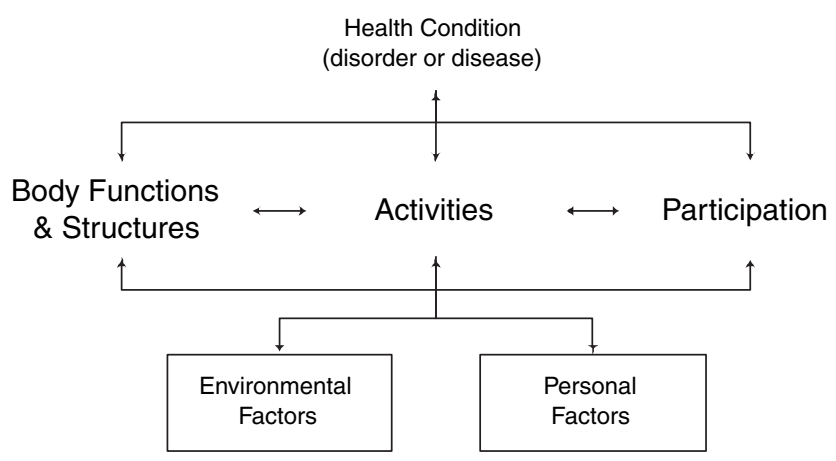

Fig. 1 Interactions between the components of the International Classification of Functioning, Disability and Health (ICF)

room at our outpatient clinic except for walking performance, which was assessed in the gymnasium of the outpatient clinic. Patients were sent the Fatigue Severity Scale (FSS) and Impact on Participation and Autonomy (IPA) questionnaires a week before they came to the clinic and were asked to complete them the day before the assessments were done. The questionnaires were checked in the presence of the patients.

\section{Measurements}

\section{Maximal isometric strength}

The maximal isometric strength of the muscles of the arms and legs was measured bilaterally using a MicroFET ${ }^{\circledR}$ hand-held dynamometer (Hoggan Health Industries Inc., Draper, Utah, USA). A Jamar $^{\circledR}$ dynamometer (Therapeutic Equipment Co., Clifton, New Jersey, USA) was used to measure handgrip strength. The reliability and validity of measurements taken with these instruments are good [11-13]. Muscle strength was measured using the 'make' test of the shoulder abductors, the elbow flexors, the wrist extensors, the hip abductors, the knee extensors, and the ankle dorsal flexors bilaterally, according to Andrews et al. [14]. Handgrip strength was measured twice on each side, according to Mathiowetz et al. [15], and the highest score for each side was noted.

\section{Sensory function}

Touch, pinprick, vibration, and joint position sense were rated according to the distal to proximal distribution of abnormalities, using the Sensory Modality Sum score (SMS) [16]. Summing the scores of all modalities yields a maximum arm sensory sum score and a maximum leg sensory sum score of 28 each.

\section{Dexterity}

The Sequential Occupational Dexterity Assessment (SODA) is a reliable and valid, performance-based test [17] in which dexterity is measured in 12 standardized tasks, such as writing, cutlery use, and picking up coins. Eighteen items are scored, with scores ranging from 0 (unable to perform the task) to 6 (able to perform the standardized task without difficulty). The range of scores on the SODA is thus 0 to 108. The SODA was chosen because this is a bimanual dexterity test, with task items problematic to patients with CIAP.

\section{Walking ability}

Because it is our experience that patients with CIAP frequently suffer from walking long distances, walking ability was assessed 
with a modified incremental Shuttle Walk Test (SWT) [18]. Patients were asked to walk around a $10-\mathrm{m}$ course marked by two cones placed $9 \mathrm{~m}$ apart, thus allowing $0.5 \mathrm{~m}$ for turning at each end. Walking speed was regulated by pre-recorded metronomic signals. The patients were asked to turn the cones at each signal. The initial walking speed was $3 \mathrm{~km} /$ hour but was increased by $0.5 \mathrm{~km} /$ hour every 2 minutes; the maximum walking speed was $7.0 \mathrm{~km} / \mathrm{hour}$. Standard instructions were given before the test and respondents were encouraged to walk as long as they could without risking falling, overuse, or pain. The use of walking aids was permitted. The test was stopped, and the number of shuttles (i.e. $10-\mathrm{m}$ courses) was noted, if patients reported severe complaints (e.g. pain or fatigue), if the patient could no longer complete the $10-\mathrm{m}$ course (the subject was not within $1 \mathrm{~m}$ of the cone at the pre-recorded signal), or when the patient completed the test (150 times the $10-\mathrm{m}$ course). Higher numbers indicate better performance on the test, with a maximum of $1500 \mathrm{~m}$. The patients were asked why they stopped if they did not complete the test. The SWT is a reliable, valid, and responsive test in different patient populations $[19,20]$. Reference values for maximum walking distance for healthy men $(\mathrm{n}=32)$ aged 50 to 70 years of the original SWT range from mean (SD) 699 (122) $\mathrm{m}$ to 727 (161) $\mathrm{m}$ [21].

\section{Fatigue}

The Dutch validated version of the FSS [22] was selected as a measure of self-reported fatigue. The FSS is a brief nine-item selfreport questionnaire with answers ranging from 1 ('strongly disagree') to 7 ('strongly agree') for each item. The mean score for the nine items ranges from 1 ('no signs of fatigue') to 7 ('most disabling fatigue') and the norm score is 2.3 points in healthy adults [22]. The FSS possesses good psychometric properties [22, 23].

\section{Balance}

The Berg Balance Scale (BBS) [24] consists of 14 items in which subjects have to complete tasks relating to balance within a certain time or cover a certain distance, such as times stepping and reaching forward. Each item is graded $0-4$. The maximum score is 56 points. The cut-off score between healthy elderly individuals who can or cannot walk safely and independently without the need of walking aids or supervision is 45 [25]. The use of walking aids was not allowed, excluding ankle-foot orthoses and orthopedic shoes. The BBS, a reliable and valid test in different populations $[25,26]$, was selected because patients with CIAP frequently report balance disorders.

\section{Autonomy}

The IPA [27] is a generic, reliable, and valid self-assessment questionnaire $[28,29]$ that measures perceived participation in social life. It contains five subscales with 31 items (autonomy indoors [7 items], autonomy outdoors [5 items], family role [7 items], social relations [6 items], and work and education [6 items]). Each item is graded on a 5-point rating scale with discrete responses, ranging from 0 (very good) to 4 (very poor). Each subscale is scored separately and is expressed in relative scores, with lower scores representing a better autonomy. In this study, the subscales autonomy indoors ( $\left(\mathrm{IPA}_{\text {indoors }}\right)$ and autonomy outdoors $\left(\right.$ IPA $\left._{\text {outdoors }}\right)$ were used because these scales contain items related to self-care, mobility indoors, the frequency of having social contacts, leisure, and mobility outdoors, items which depend to a great extent on the individuals' general functional mobility.

\section{Data analysis}

Descriptive statistics were used to assess functioning. Scores were calculated for the whole group, as well as subgroups determined by MRS scores. We calculated muscle strength Z-scores using reference values for healthy adults $[15,30]$. Data reduction was performed by calculating mean Z-scores for the arms (Z-scores for shoulders, elbows, and wrists/handgrip), and the legs (Z-scores for hips, knees, and ankles). The internal consistency of the SMS, SODA, FSS, BBS, and IPA $\mathrm{A}_{\text {indoors }}$ and IPA $\mathrm{A}_{\text {outdoors }}$ was also assessed.

We analyzed the associations between variables in two consecutive steps. First, correlation analyses (Pearson's r) were performed between single body functions, activities, and participation outcome measures, as well as personal and environmental factors (Fig. 1). Then hierarchical multiple univariate linear regression analysis (stepwise procedure) was carried out to investigate which body functions (muscle strength, sensory function, pain, fatigue, and balance) best explain variance in activity scores (walking ability and dexterity) and participation (autonomy), as well as which activities best explain variance in participation scores. We adjusted for age and the use of walking aids. The strength of the association between the dependent variable and the independent variables is expressed as a percentage (adjusted $R^{2} \times 100$ ), and the relative importance of the independent variables is given as a standardized coefficient beta. Analyses were performed using the Statistical Package for Social Sciences (version 11.5). All tests were two-sided and $\mathrm{P}$ values $<0.05$ were considered significant.

\section{Results}

Demographic characteristics and functional outcome measures of all participants are presented for the whole group, as well as for the MRS subgroups (Table 1). The internal consistency of the SMS, SODA, FSS, BBS, and IPA $A_{\text {indoors }}$ and IPA $A_{\text {outdoors }}$ in this study was good (Cronbach's $\alpha$ : 0.87, 0.87, 0.95, 0.95, 0.94, and 0.87 respectively).

\section{Functional outcome measures}

Dexterity was only slightly affected in the whole group and in the subgroups. The test items handling $a$ spoon, buttoning a blouse, writing a sentence, and picking up coins had the lowest mean scores.

With regard to leg functioning, the mean scores on the SWT varied widely (range 0-150). Different reasons were given for stopping the SWT: 40 patients could not reach the last cone on time, and these patients complained about tired legs (14 patients), 'blocking' of the legs (i.e. the legs could not move the body faster without pain, cramp etc.) (13 patients), pain in the legs ( 7 patients), fatigue (4 patients), and numb legs (2 patients). Eight patients reached the cone in time, but stopped the test because of numb legs (4 patients), fatigue ( 3 patients), or pain ( 1 patient). Four patients completed all 150 shuttles (i.e. $15010-\mathrm{m}$ courses). Three patients could not walk the first $10 \mathrm{~m}$ within the given time limit of less than 12 seconds and scored zero. The reason why one patient stopped the test could not be retrieved.

The FSS scores also varied widely. Of the total study group, 2 patients experienced no fatigue at all (score 1.0) whereas 32 patients reported substantial 
Table 1 Demographic characteristics and functional outcome of 56 patients with chronic idiopathic axonal polyneuropathy

\begin{tabular}{|c|c|c|c|c|c|}
\hline & Variable/Instrument & $\begin{array}{l}\text { MRS total } \\
\mathrm{n}=56(100 \%)\end{array}$ & $\begin{array}{l}\text { MRS score } 1 \\
\mathrm{n}=19(34 \%)\end{array}$ & $\begin{array}{l}\text { MRS score } 2 \\
\mathrm{n}=30(54 \%)\end{array}$ & $\begin{array}{l}\text { MRS score } 3 \\
n=7(12 \%)\end{array}$ \\
\hline \multirow[t]{3}{*}{ Demographics } & Age, years & $\begin{array}{l}67.8 \\
(8.6)\end{array}$ & $\begin{array}{l}66.1 \\
(8.4)\end{array}$ & $\begin{array}{l}67.7 \\
(8.9)\end{array}$ & $\begin{array}{l}73 \\
(7.1)\end{array}$ \\
\hline & Gender (male; female, $\mathrm{n}$ ) & $45 ; 11$ & $15 ; 4$ & $25 ; 5$ & $5 ; 2$ \\
\hline & Disease duration, years & $\begin{array}{l}10.5 \\
(6.5)\end{array}$ & $\begin{array}{l}9 \\
(6.4)\end{array}$ & $\begin{array}{l}11 \\
(6.8)\end{array}$ & $\begin{array}{l}12.6 \\
(5.6)\end{array}$ \\
\hline \multirow[t]{4}{*}{ Arm functioning } & Maximal isometric strength (HHD, z-score) & $\begin{array}{l}-0.1 \\
(0.9)\end{array}$ & $\begin{array}{l}0.4 \\
(0.7)\end{array}$ & $\begin{array}{l}-0.2 \\
(0.8)\end{array}$ & $\begin{array}{l}-0.7 \\
(1.1)\end{array}$ \\
\hline & Sensory function (SMS, 0-28 points) & $\begin{array}{l}28.0 \\
(6 \text { to } 28)\end{array}$ & $\begin{array}{l}28 \\
\text { (26 to } 28 \text { ) }\end{array}$ & $\begin{array}{l}27.5 \\
(6 \text { to } 28)\end{array}$ & $\begin{array}{l}26 \\
\text { (17 to } 28 \text { ) }\end{array}$ \\
\hline & Pain $(n(\%))$ & $\begin{array}{l}20 \\
(36)\end{array}$ & $\begin{array}{l}4 \\
(21)\end{array}$ & $\begin{array}{l}13 \\
(43)\end{array}$ & $\begin{array}{l}3 \\
(43)\end{array}$ \\
\hline & Dexterity (SODA, 0-108 points) & $\begin{array}{l}105.0 \\
\text { (76 to 108) }\end{array}$ & $\begin{array}{l}106 \\
\text { (97 to } 108)\end{array}$ & $\begin{array}{l}102 \\
\text { (82 to } 108)\end{array}$ & $\begin{array}{l}96 \\
\text { (76 to } 108)\end{array}$ \\
\hline \multirow[t]{9}{*}{ Leg functioning } & Maximal isometric strength (HHD, z-score) & $\begin{array}{l}-1.9 \\
(1.0)\end{array}$ & $\begin{array}{l}-1.2 \\
(0.7)\end{array}$ & $\begin{array}{l}-2.1 \\
(0.9)\end{array}$ & $\begin{array}{l}-2.6 \\
(0.9)\end{array}$ \\
\hline & Sensory function (SMS, 0-28 points) & $\begin{array}{l}15.0 \\
\text { (4 to 28) }\end{array}$ & $\begin{array}{l}16 \\
\text { (9 to } 28)\end{array}$ & $\begin{array}{l}15 \\
\text { (5 to } 22 \text { ) }\end{array}$ & $\begin{array}{l}13 \\
\text { (4 to } 18)\end{array}$ \\
\hline & Pain $(n(\%))$ & $\begin{array}{l}43 \\
(77)\end{array}$ & $\begin{array}{l}15 \\
(79)\end{array}$ & $\begin{array}{l}24 \\
(80)\end{array}$ & $\begin{array}{l}4 \\
(57)\end{array}$ \\
\hline & Walking perf. (SWT, 0-150 10-m. courses) & $\begin{array}{l}60.4 \\
(44.6)\end{array}$ & $\begin{array}{l}101.0 \\
(37.9)\end{array}$ & $\begin{array}{l}44.9 \\
(32.3)\end{array}$ & $\begin{array}{l}16.3 \\
(14.8)\end{array}$ \\
\hline & Use of walking aids (n(\%)) & $\begin{array}{l}18 \\
(32)\end{array}$ & $\begin{array}{l}1 \\
(5)\end{array}$ & $\begin{array}{l}11 \\
(37)\end{array}$ & $\begin{array}{l}6 \\
(86)\end{array}$ \\
\hline & Fatigue (FSS, 1-7 points) & $\begin{array}{l}4.5 \\
\text { (1 to } 7)\end{array}$ & $\begin{array}{l}2.7 \\
(1.0 \text { to } 5.4)\end{array}$ & $\begin{array}{l}5.2 \\
\text { (1.7 to } 7.0)\end{array}$ & $\begin{array}{l}5.3 \\
(1.6 \text { to } 7.0)\end{array}$ \\
\hline & Balance (BBS, 0-56 points) & $\begin{array}{l}54.0 \\
(13 \text { to } 56 \text { ) }\end{array}$ & $\begin{array}{l}56 \\
(48 \text { to } 56)\end{array}$ & $\begin{array}{l}54 \\
(30 \text { to } 56)\end{array}$ & $\begin{array}{l}22 \\
(13 \text { to } 56)\end{array}$ \\
\hline & Autonomy indoors (IPA, 0-4 points) & $\begin{array}{l}1.0 \\
(0 \text { to } 2.1)\end{array}$ & $\begin{array}{l}0 \\
(0 \text { to } 1.7)\end{array}$ & $\begin{array}{l}1.0 \\
(0 \text { to } 2.1)\end{array}$ & $\begin{array}{l}1.1 \\
(0.6 \text { to } 1.9)\end{array}$ \\
\hline & Autonomy outdoors (IPA, 0-4 points) & $\begin{array}{l}1.4 \\
(0 \text { to } 3.4)\end{array}$ & $\begin{array}{l}0.6 \\
(0 \text { to } 1.6)\end{array}$ & $\begin{array}{l}1.8 \\
\text { (0 to } 2.8 \text { ) }\end{array}$ & $\begin{array}{l}2.4 \\
\text { (1.4 to } 3.4)\end{array}$ \\
\hline
\end{tabular}

Values are mean (SD) or median (range) unless stated otherwise

HHD, hand-held dynamometry; SMS, sensory modality score; SODA, sequential occupational dexterity assessment; SWT, modified shuttle walk test; FSS, fatigue severity scale; BBS, Berg Balance Scale; IPA, impact on participation and autonomy questionnaire; MRS, Modified Rankin Scale: $0=$ no symptoms at all; $1=$ no significant disability despite symptoms: able to carry out all usual duties and activities; 2 = slight disability: unable to carry out all previous activities but able to look after own affairs without assistance; 3 = moderate disability: requiring some help, but able to walk without assistance; $4=$ moderately severe disability: unable to walk without assistance, and unable to attend to own bodily needs without assistance; 5 = severe disability: bedridden, incontinent, and requiring constant nursing care and attention

fatigue (FFS score $>4.0$ ), 4 of them scoring 7.0, the most disabling level of fatigue. Strikingly, the mean score of the test item fatigue is among my three most disabling symptoms was $2.47,4.50$, and 4.57 in the MRS subgroups 1, 2, and 3 respectively.

Forty-nine patients scored $\geq 45$ points on the BBS, 17 of whom scored 56 points, i.e. optimal balance. The test item standing on one foot had the lowest mean score of 2.66 points.

Patients' self-reported autonomy was slightly worse outdoors (median 1.4) than indoors (median $1.0)$. Only one patient scored more than 2.0 on IPA $A_{\text {indoors }}$, whereas 17 patients scored 2.0 or more on IPA $A_{\text {outdoors, }}$ which means that they experienced significant problems in autonomy outdoors. The IPA $_{\text {indoors }}$ item my chances of getting around in my house where I want to are... (mean 1.11) and the IPA $_{\text {outdoors }}$ item my chances of going on the sort of trips and holidays I want to go on are... (mean 1.88) had the worst scores (i.e. highest scores) in the total patient group.

\section{Correlation studies}

Moderate Pearson correlation coefficients were found

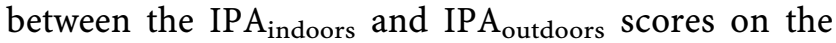
one hand, and the SWT and FSS scores on the other (Table 2), meaning that patients who reported having good autonomy had a good walking ability and reported almost no fatigue. Strikingly, post-hoc analysis showed a higher correlation between balance and muscle strength of the legs $(r=0.57(\mathrm{p}<0.01))$, than between balance and sensory function of the legs $(\mathrm{r}=0.01 \quad$ (n.s.) $)$. Correlations between muscle strength or sensory function of the legs and fatigue were $r=0.40(p<0.01)$ and $r=0.22$ (n.s.) respec- 
Table 2 Pearson correlation of variables related to demographic features, arm and leg functioning, fatigue, balance, and autonomy

\begin{tabular}{|c|c|c|c|c|c|}
\hline & & SODA & SWT & IPAindoors & IPAoutdoors \\
\hline \multirow{6}{*}{ Arm funct. } & Age & -0.14 & -0.53 & 0.25 & 0.36 \\
\hline & Disease duration & -0.24 & -0.40 & 0.28 & 0.45 \\
\hline & Maximal isometric strength (HHD) & 0.48 & & -0.42 & \\
\hline & Sensory function (SMS) & 0.41 & & -0.23 & -0.33 \\
\hline & Pain & -0.22 & & 0.07 & 0.18 \\
\hline & Dexterity (SODA) & & & -0.35 & \\
\hline \multirow[t]{7}{*}{ Leg funct. } & Maximal isometric strength (HHD) & & 0.51 & -0.42 & -0.47 \\
\hline & Sensory function (SMS) & & 0.22 & -0.41 & -0.31 \\
\hline & Pain & & 0.14 & -0.02 & -0.10 \\
\hline & Walking performance (SWT) & & & -0.65 & -0.71 \\
\hline & Walking aids/foot orthoses & & -0.60 & 0.45 & 0.53 \\
\hline & Fatigue (FSS) & & -0.53 & 0.62 & 0.64 \\
\hline & Balance (BBS) & & 0.52 & -0.37 & -0.50 \\
\hline
\end{tabular}

Italics: $p<0.05$; bold: $p<0.01$

HHD, hand-held dynamometry; SMS, sensory modality score; SODA, sequential occupational dexterity assessment; SWT, modified shuttle walk test; FSS, fatigue

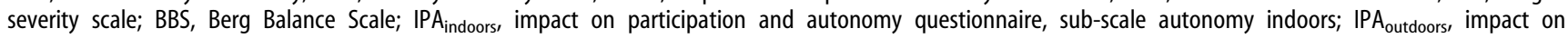
participation and autonomy questionnaire, sub-scale autonomy outdoors

tively. Analysis of the correlation coefficients revealed no multicollinearity $(r \geq 0.90)$.

The results from the hierarchical linear regression analyses (stepwise procedure) for arm functioning are shown in Fig. 2a. Muscle strength and sensory function together explained almost $30 \%$ of the total variance in SODA scores, after adjustment for age. Even less variance was explained by muscle strength and dexterity on one hand, and autonomy indoors on the other $(17 \%$ and $13 \%$, respectively). With regard to leg functioning (Fig. 2b), 63\% of the variance in SWT scores was explained by age, muscle strength and fatigue. Sensory function and fatigue, and balance and fatigue accounted for $46 \%$ and $56 \%$ of the variance in the IPA $_{\text {indoors }}$ and the IPA $A_{\text {outdoors }}$ scores, respectively, after adjustment for age and the use of walking aids. On the basis of the beta values, fatigue was the main determinant $(\beta=0.504$ and $\beta=0.561$, respectively). Walking performance explained $42 \%$ and $49 \%$ of the variance in the IPA $A_{\text {indoors }}$ and the IPA $A_{\text {outdoors }}$ scores, respectively. Again, the results were not substantially different after adjustment for age and the use of walking aids. All percentages were significant $(\mathrm{p}<0.01)$.

\section{Discussion}

This is the first detailed study of the functioning of patients with CIAP. Besides known impairments of muscle strength, sensory function, and pain, we showed that fatigue and walking disability markedly interfere with patients' functioning in daily life.

The importance of patients' walking ability is shown by the finding that walking ability explained $42 \%$ of the variance in autonomy indoors and $49 \%$ of the variance in autonomy outdoors. Moreover, 33 patients mentioned walking as their most limiting activity in daily life, with other activities such as maintaining a standing position ( 7 patients), transferring (3 patients), manipulations of the hands (1 patient) being mentioned less frequently. Twenty-four patients had serious walking limitations, with SWT scores $\leq 50$ and a maximum walking velocity of $4.5 \mathrm{~km} /$ hour. These values are lower than reference values for maximum walking distance and maximum walking speed in healthy adults $[21,31]$. In the literature, the validity and reliability of the SWT were based on assessment of endurance in patients with cardiorespiratory failure. In our study, 7 patients stopped the test because of cardiorespiratory failure whereas 44 patients stopped because of neurological symptoms. The 7 patients suffered from chronic heart failure (3 patients) and COPD (2 patients), or had a history of cardiac bypass surgery (2 patients). Eight patients stopped the test because of pain in the legs. These patients did not habitually suffer from intermittent claudication. Muscle strength and fatigue, when adjusted for age and the use of walking aids, explained $63 \%$ of the variation in walking ability scores, leaving thus $37 \%$ unexplained. This unexplained percentage may be attributed in part to psychological factors such as perceived behaviour control over activities. Recently, Schröder et al. (accepted) [32] showed that such control perceptions explained $9 \%$ of the variance in SWT performance in patients with CIAP.

Thirty-two patients reported substantial fatigue. Surprisingly, most of these patients considered their autonomy indoors and outdoors as being quite satisfactory (IPA $A_{\text {indoors }}$ score $<2.0$ in 55 patients, IPA $_{\text {outdoors }}$ score $<2.0$ in 39 patients). Fatigue cor- 
A

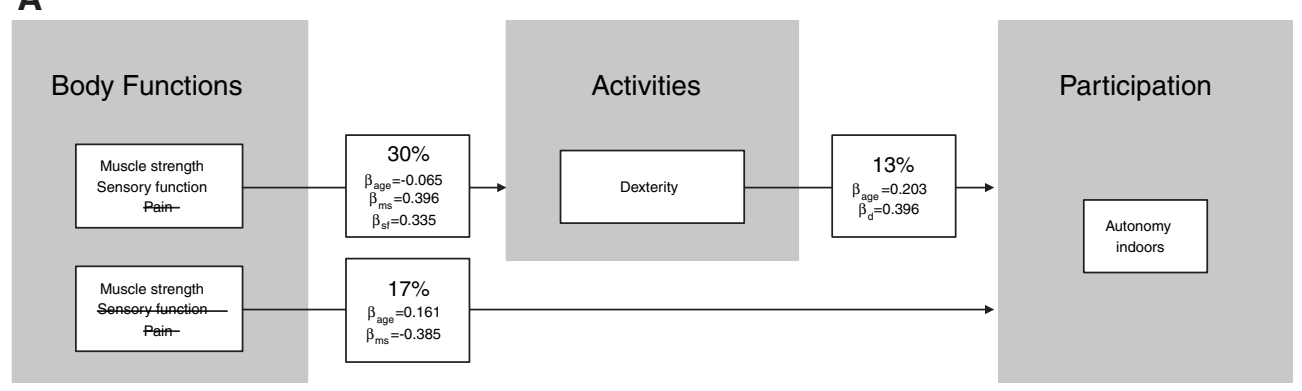

B

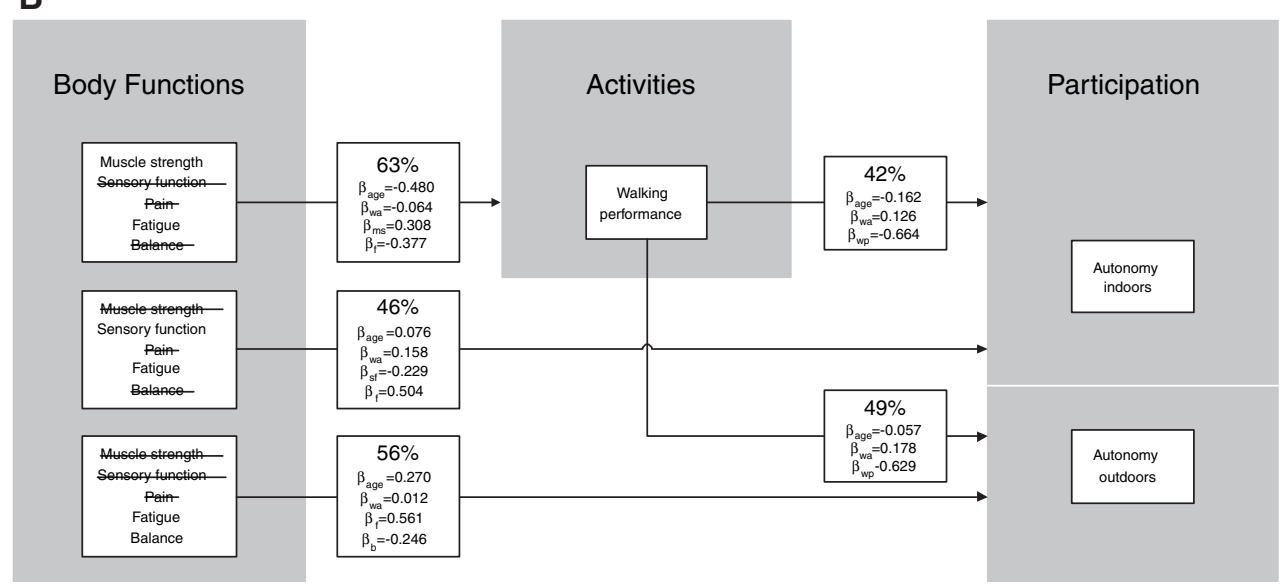

Fig. 2 Linear regression analysis of associations between body functions, activities, and participation, for arm functioning (A) and leg functioning (B), after adjustment for age (A and B) and the use of walking aids (B). Interpretation (Figure 2A, box starting with 30\%): analysis of the effect of independent body functions (represented by muscle strength, sensory function, and pain) on dependent activity (represented by dexterity), resulted in a model explaining a total of $30 \%$ (Adjusted $R^{2} \times 100$ ) of the total variance in dexterity scores, when adjusted for age, with a significance of $p<0.01$. Pain was eliminated as contributing variable in the stepwise procedure. The relative contribution of the independent variables is expressed as $\beta$, the standardized coefficient beta. $\beta_{\text {age }}$, beta age; $\beta_{\mathrm{ms}}$, beta muscle strength. $\beta_{\mathrm{sf}}$, beta sensory function; $\beta_{\mathrm{d}}$, beta dexterity; $\beta_{\mathrm{wa}}$, beta walking aids; $\beta_{\mathrm{f}}$, beta fatigue; $\beta_{\mathrm{b}}$, beta balance; $\beta_{\mathrm{wp}}$, beta walking performance. In Figure $2 \mathrm{~A}$, box $30 \%$ : when dexterity on the SODA is improved by 1 point, age is increased by -0.065 years, muscle strength is increased by $0.396 \mathrm{Z}$-score, and sensory function is increased by 0.335 points

related fairly well with patients' walking ability and autonomy, and contributed substantially to the variance in walking ability and perceived autonomy outdoors in all 56 patients. Therefore, next to walking ability, fatigue seems to be important to patient's functioning. A comparable relationship between fatigue and physical functioning has been found in patients with immune-mediated polyneuropathies [23], and in patients with facioscapulohumeral muscular dystrophy, hereditary motor and sensory neuropathy type I, and adult onset myotonic dystrophy [33]. Future studies should determine whether fatigue is a consequence of axonal degeneration or of the limited walking ability, and whether fatigue can be counteracted by interventions such as exercise training.

The balance test scores were relatively high, which suggests that the patients had only minor problems with balance. However, in our experience patients with CIAP often complain about balance problems during motor performance when there is less visual control (e.g. walking or standing in the dark), or during so-called 'double tasking', which suggests that more demanding tests of balance should be used.

As reported earlier for chronic axonal polyneuropathy, we also found functioning of the arms to be affected less than that of the legs in patients with CIAP. Sensory function and muscle strength explained only $30 \%$ of the variation in dexterity scores, which may be because the SODA assesses not only muscle strength related tasks (e.g. unscrewing a bottle) but also manipulative tasks (e.g. buttoning a blouse). Post-hoc analysis showed that patients had more difficulty with the manipulative tasks. Also, the tasks in general may not have been demanding enough.

Seven patients were classified MRS score 3, which is relatively high compared with the numbers reported in other studies of patients with CIAP $[2,16]$. As in the other studies, this was probably due to comorbidity. In our tertiary referral center patients are often referred to our outpatient department after previous evaluation by other neurologists. Patients 
with mild disease are therefore probably less represented, although there are still 19 patients with MRS score 1 included. Overall, sensory function and age seemed less relevant to functioning, which is in accordance with Vrancken et al. [34]. Although patients with CIAP do experience sensory dysfunction and pain, their balance, walking ability, and autonomy seem not to be severely influenced by these impairments. Instead, the most relevant parameters were muscle strength, fatigue, and walking ability, all of which may benefit from therapeutic exercise. For example, it has been shown that fatigue and muscle strength improve after bicycle exercise training in patients with inflammatory neuropathy [35]. We believe that future studies should focus on improving the walking ability and balance of patients with CIAP, and on decreasing fatigue by means of functional training. A potential limitation of our study is that the instruments we used were all psychometrically validated in non-CIAP patients. However, the high internal consistency of the BBS, FSS, SODA, and IPA, and the outcome on the SWT, might support the usefulness of these tests in patients with CIAP but need to be validated. Consequently, these clinimetric tools - apart from the BBS - can be recommended for use in both research and clinical settings, in addition to the MRS, whenever functioning needs to be assessed. However, further investigations are necessary.

In conclusion, strength, fatigue, and walking ability are a problem in patients with CIAP and adversely affect patient autonomy. Patients with CIAP can be classified by means of the frequently used MRS; however, more detailed information about functioning can be obtained with the FSS and the SWT. The instruments used in this study seem to be of clinical relevance, although a more demanding, multitask instrument for balance should be used. Patients with CIAP might benefit from therapeutic exercise. Future studies, preferably with a longitudinal design, should shed light on the determinants of functioning in these patients and evaluate potential interventions.

\section{Reference}

1. McLeod JG, Tuck RR, Pollard JD, Cameron J, Walsh JC (1984) Chronic polyneuropathy of undetermined cause. J Neurol Neurosurg Psychiatry 47:530535

2. Notermans NC, Wokke JHJ, Franssen $\mathrm{H}$, van der Graaf $\mathrm{Y}$, Vermeulen $\mathrm{M}$, van den Berg LH, Bar PR, Jennekens FG (1993) Chronic idiopathic polyneuropathy presenting in middle or old age: a clinical and electrophysiological study of 75 patients. J Neurol Neurosurg Psychiatry 56:1066-1071

3. Notermans NC, Wokke JHJ, van der Graaf Y, Franssen H, van Dijk GW, Jennekens FG (1994) Chronic idiopathic axonal polyneuropathy: a five year follow up. J Neurol Neurosurg Psychiatry 57:1525-1527

4. Hughes RAC, Umapathi T, Gray IA, Gregson NA, Noori M, Pannala AS, Proteggente A, Swan AV (2004) A controlled investigation of the cause of chronic idiopathic axonal polyneuropathy. Brain 127:1723-1730

5. World Health Organization (2001) International classification of functioning, disability and health: ICF. Geneva

6. Merkies IS, Schmitz PI, van der Meche FG, Samijn JP, van Doorn PA (2003) Connecting impairment, disability, and handicap in immune mediated polyneuropathies. J Neurol Neurosurg Psychiatry 74:99-104
7. Erdmann PG, van Meeteren NLU, Kalmijn S, Wokke JHJ, Helders PJM, van den Berg LH (2005) Functional health status of patients with chronic inflammatory neuropathies. J Peripher Nerv Syst 10:181-189

8. van Genderen FR, van Meeteren NLU, Heijnen L, van den Berg HM, Helders PJM (2005) The use of a disability model in haemophilia research. Haemophilia 11:472-480

9. van Swieten JC, Koudstaal PJ, Visser MC, Schouten HJ, van Gijn J (1988) Interobserver agreement for the assessment of handicap in stroke patients. Stroke 19:604-607

10. Kissel JT, (2003) The treatment of chronic inflammatory demyelinating polyradiculoneuropathy. Semin Neurol 23:169-80

11. Deones VL, Wiley SC, Worrell T (1994) Assessment of quadriceps muscle performance by a hand-held and an isokinetic dynamometer. J Orthop Sports Phys Ther 20:296-301

12. Kilmer DD, McCrory MA, Wrigth NC, Rosko RA, Kim HR, Aitkens SG (1997) Hand-held dynamometry reliability in persons with neuropathic weakness. Arch Phys Med Rehabil 78:1364-1368

13. Mathiowetz V, Weber K, Volland G, Kashman N (1984) Reliability and validity of grip and pinch strength evaluations. J Hand Surg 9a:222-226
14. Andrews AW, Thomas MW, Bohannon RW (1996) Normative values for isometric muscle force measurements obtained with hand-held dynamometers. Phys Ther 76:248-259

15. Mathiowetz V, Kashman N, Volland G, Weber K, Dowe M, Rogers S (1985) Grip and pinch strength: normative data for adults. Arch Phys Med Rehabil 66:69-74

16. Teunissen LL, Notermans NC, Franssen $\mathrm{H}$, van der Graaf Y, Oey PL, Linssen WH, van Engelen BG, Ippel PF, van Dijk GW, Gabreels-Festen AA, Wokke JH (1997) Differences between hereditary motor and sensory neuropathy type 2 and chronic idiopathic axonal neuropathy. A clinical and electrophysiological study. Brain 120:955-962

17. van Lankveld W, van 't Pad Bosch $P$, Bakker J, Terwindt S, Franssen M, van Riel P (1996) Sequential Occupational Dexterity Assessment (SODA): a new test to measure hand disability. J Hand Ther 9:27-32

18. Singh SJ, Morgan MDL, Scott S, Walters D, Hardman AE (1992) Development of a shuttle walking test of disability in patients with chronic airways obstruction. Thorax 47:1019-1024

19. Solway S, Brooks D, Lacasse Y, Thomas S (2001) A qualitative systematic overview of the measurement properties of functional walk tests used in the cardiorespiratory domain. Chest 119:256-270 
20. Bradley J, Howard J, Wallace E, Elborn S (2000) Reliability, repeatability, and sensitivity of the modified shuttle test in adult cystic fibrosis. Chest 117:16661671

21. Webb HF, Lawrence J, Jones PR, Singh SJ, Morgan MD (2002) Age-related standards for performance in the incremental shuttle walking test: a pilot study in healthy men aged 40-69 years. Eur Respir J 20(Suppl. 38):67s

22. Krupp LB, LaRocca NG, Muir-Nash J, Steinberg AD (1989) The fatigue severity scale. Application to patients with multiple sclerosis and systemic lupus erythematosus. Arch Neurol 46:11211123

23. Merkies ISJ, Schmitz PIM, Samijn JPA, van der Meche FGA, van Doorn PA, for the European Inflammatory Neuropathy Cause and Treatment (INCAT) Group (1999) Fatigue in immune-mediated polyneuropathies. Neurology 53:1648-1654

24. Berg K, Wood-Dauphinee S, Williams JI, Gayton D (1989) Measuring balance in the elderly: preliminary development of an instrument. Phys Can 41:304-311
25. Berg KO, Wood-Dauphinee SL, Williams JI, Maki B (1992) Measuring balance in the elderly: validation of an instrument. Can J Publ Health 83(suppl.2):s7-s11

26. Berg K, Wood-Dauphinee S, Williams JI (1995) The balance scale: reliability assessment with elderly residents and patients with an acute stroke. Scan J Rehabil Med 27:27-36

27. Cardol M, De Haan RJ, van den Bos GA, De Jong BA, De Groot IJM (1999) The development of a handicap assessment questionnaire: the Impact on Participation and Autonomy (IPA). Clin Rehabil 13: 411-419

28. Cardol M, de Haan RJ, de Jong BA, van den Bos GA, de Groot IJM (2001) Psychometric properties of the Impact on Participation and Autonomy Questionnaire. Arch Phys Med Rehabil 82: 210216

29. Cardol M, Beelen A, van den Bos GA, de Jong BA, de Groot IJ, de Haan RJ (2002) Responsiveness of the Impact on Participation and Autonomy questionnaire. Arch Phys Med Rehabil 83:1524-1529

30. Bohannon RW (1997) Reference values for extremity muscle strength obtained by hand-held dynamometry from adults aged 20-79 years. Arch Phys Med Rehabil 78:26-32
31. Bohannon RW (1997) Comfortable and maximum walking speed of adults aged 20-79 years: reference values and determinants. Age Ageing 26:15-19

32. Schröder CD, Johnston M, Teunissen LL, Notermans NC, Helders PJM, van Meeteren NLU (2006) Perceived control is a concurrent predictor of activity limitations in patients with Chronic idiopathic Axonal Polyneuropathy (CIAP). Arch Phys Med Rehabil, in press

33. Kalkman JS, Schillings ML, van der Werf SP, Padberg GW, Zwarts MJ, van Engelen BGM, Bleijenberg G (2005) Experienced fatigue in facioscapulohumeral dystrophy, myotonic dystrophy, and HMSN-I. J Neurol Neurosurg Psychiatry 76:1406-1409

34. Vrancken AFJE, Franssen H, Wokke JHJ, Teunissen LL, Notermans NC (2002) Chronic idiopathic axonal polyneuropathy and successful aging of the peripheral nervous system in elderly people. Arch Neurol 59:533-540

35. Garssen MP, Bussmann JB, Schmitz PI, Zandbergen A, Welter TG, Merkies IS, Stam HJ, van Doorn PA (2004) Physical training and fatigue, fitness, and quality of life in Guillain-Barré syndrome and CIDP. Neurology 63:2393-2395 